\title{
Nilai Moral Figur Putri Mandalika dalam Profesi Akuntan
}

\author{
Ika Putri Fitri Ajiani ${ }^{1}$ \\ Fakultas Ekonomi dan Bisnis \\ Universitas Airlangga, Indonesia \\ Email: ika.putri.fitri-2018@feb.unair.ac.id
}

\author{
Hamidah $^{2}$ \\ Fakultas Ekonomi dan Bisnis \\ Universitas Airlangga, Indonesia
}

\begin{abstract}
ABSTRAK
Penelitianini berangkat daricerita legenda Putri Mandalika yang menjadi dasar untuk nilai moral figur Putri Mandalika dilihat dalam profesi akuntan, khususnya perempuan. Nilai moral tersebut terdiri dari nilai pengorbanan dan nilai emansipasi. Penelitianini menggunakan pendekatan fenomenologi. Teknik pengumpulan data menggunakan teknik wawancara terstruktur. Informan yang menjadi objek penelitian adalah Budayawan dan Praktisi Profesi Akuntan. Hasil penelitian ini menunjukkan bahwa nilai pengorbanan dan nilai emansipasi figur Putri Mandalika masih hidup dalam profesi akuntan, khususnya perempuan.
\end{abstract}

Kata Kunci: Nilai Pengorbanan; Nilai Emansipasi; Putri Mandalika; Profesi Akuntan.

\section{Moral Value of Putri Mandalika's Figure in Accountant Profession}

\section{ABSTRACT}

This study departs from the legendary story of Princess Mandalika which is the basis for the moral values of the figure of the Princess Mandalika seen in the accounting profession, especially women. The moral value consists of the value of sacrifice and the value of emancipation. This research uses a phenomenological ap proach. Data collection techniques using semi-structured interview techniques. The informants who are the object of research are the Culture and Professional Practitioners of Accountants. The results of this study indicate that the value of sacrifice and the value of the emancipation of the figure of Princess Mandalika are still alive in the accounting profession, especiallywomen.

Keywords: $\quad$ Sacrifice Value; Emancipation Value; Putri Mandalika; Professional Accountant.

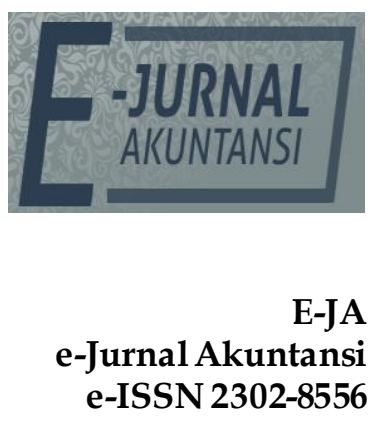

Vol. 30 No. 4

Denpasar, April 2020

Hal. 922-931

Artikel Masuk: 5 Februari 2020

Tanggal Diterima: 1 April 2020 


\section{PENDAHULUAN}

Nama Mandalika tidak hanya digunakan sebagai nama tempat wisata di Lombok, melainkan juga sebagai "icon" dari sebuah acara seperti Festival Pesona Bau Nyale yang selalu diadakan setiap tahunnya. Secara umum, Festival Pesona Bau Nyale diadakan tidak hanya memberikan kesenangan dan menghibur para penikmatnya, melainkan juga mengandung pesan moral dari Cerita Mandalika Nyale atau Bau Nyale untuk masyarakat suku sasak kemudian dijadikan sebagai pegangan hidup di kehidupan sehari-hari dalam hubungan antar sesama warga masyarakat khususnya di kalangan suku sasak. Bagi masyarakat sasak, tradisi "bau nyale" dianggap sebagai penghormatan terhadap tokoh legenda Putri Mandalika. Dalam cerita legenda Putri Mandalika, diperkenalkan seorang Putri Kerajaan Raja Tonjang Beru dan Dewi Seranting yang bernama Putri Mandalika (Ariefa \& Mutiawanthi, 2018), (Hartono \& Faozaeni, 2018), (Rosnilaw ati, 2016) dan (Sasangka, 2002). Putri Mandalika yang terkenal akan kecantikan dan pesonanya diperebutkan oleh pangeran-pangeran dari seluruh kerajaan yang ada di Lombok. Dikarenakan sang Putri tidak ingin terjadi perpecahan dan pertempuran di Bumi Sasak, maka di Pantai Kuta Lombok menjelang Subuh pada tanggal 20 bulan ke 10 menurut perhitungan bulan Sasak sang Putri pun meloncat ke dalam laut. Setelah beberapa saat, muncul sekumpulan cacing laut berwarna-warni (Nyale) yang menurut kepercayaan masyarakat setempat merupakan jelmaan dari Putri Mandalika (Ariefa \& Mutiawanthi, 2018), (Hartono \& Faozaeni, 2018), (Purna, 2018), (Rosnilawati, 2016), dan (Sasangka, 2002).

Cerita legenda Putri Mandalika banyak memberikan nilai-nilai moral yang tersirat dari figur Putri Mandalika dan dapat dipelajari lebih dalam. Jika dikaitkan antara cara sang Putri Mandalika rela mengorbankan nyawanya d emi kepentingan masyarakat hampir sama dengan nilai yang ada pada profesi akuntan. Profesi akuntan juga bersedia menerima tanggung jawab untuk bertindak demi kepentingan publik sebagai peran yang sangat vital dan ciri yang membedakan dengan profesi yang lain. Terutama bagi profesi akuntan publik, sangat tegas diatur bahwa tanggung jawab seorang akuntan tidak hanya terbatas pada kepentingan klien, melainkan juga untuk kepentingan publik. Dalam bertugas sebagai Akuntan Profesional, perlu memerhatikan dan mematuhi ketentuan Kode Etik yang berlaku. Sebagai Akuntan Profesional juga dituntut untuk melakukan layanan profesionalnya dengan kualitas terbaik sebagaimana tercantum dalam pernyataan misi AICPA. Prinsip tersebut menyerukan perilaku terhormat, bahkan dengan mengorbankan kepentingan pribadi (Akenbor \& Tennyson, 2014) dan (Collins \& Schultz, 1995).

Jika menurut perspektif cerita legenda Putri Mandalika kepentingan publik adalah dengan menjaga kedamaian dan memberikan manfaat sebanyak mungkin (bau nyale) kepada rakyatnya (Sasangka, 2002), maka bagaimana dengan akuntan perempuan masa kini?, terutama yang sudah berada pada tingkat top management tentu banyak mengorbankan kepentingan pribadinya dibandingkan akuntan laki-laki karena harus berperan sebagai ibu, istri, dan akuntan sekaligus. Pertanyaan yang mungkin timbul adalah: sejauh mana 
akuntan perempuan masa kini mengorbankan kepentingan pribadinya untuk melayani kepentingan publik?

Nilai lainnya yang melekat pada diri Putri Mandalika juga yaitu nilai emansipasi. Hal yang mencolok dimana seorang Putri Mandalika memiliki aspek feminisme dan maskulinitas yang mencerminkan nilai emansipasi antara kaum perempuan dengan kaum lelaki dalam berbagai bidang dan aspek kehidupan. Aspek feminisme dari Putri Mandalika yaitu memiliki budi pekerti yang mulia, selalu menghormati dan menghargai orang lain, cerdas, arif dan bijaksana, sabar dan lemah lembut. Jiwa seperti ini merupakan jiwa kewanitaan, yang secara psikologis, wanita memiliki perasaan dan nurani halus serta keibuan, yang selalu mudah mengalah, berpikir panjang, mampu mengontrol dan mengendalikan emosinya, nalurinya mampu memahami dan mengerti perasaan orang lain, ramah, pemurah dan perhatian terhadap sesama (Purna, 2018).

Nilai emansipasi yang telah lama dicerminkan oleh sosok Putri Mandalika di masa lampau ternyata masih menjadi topik menarik pada masa kini. Oleh karena itu, peneliti termotivasi untuk mengkaji secara mendalam bagaimana nilai-nilai moral yang terkandung dalam figur Putri Mandalika dilihat dalam diri profesi akuntan perempuan masa kini.

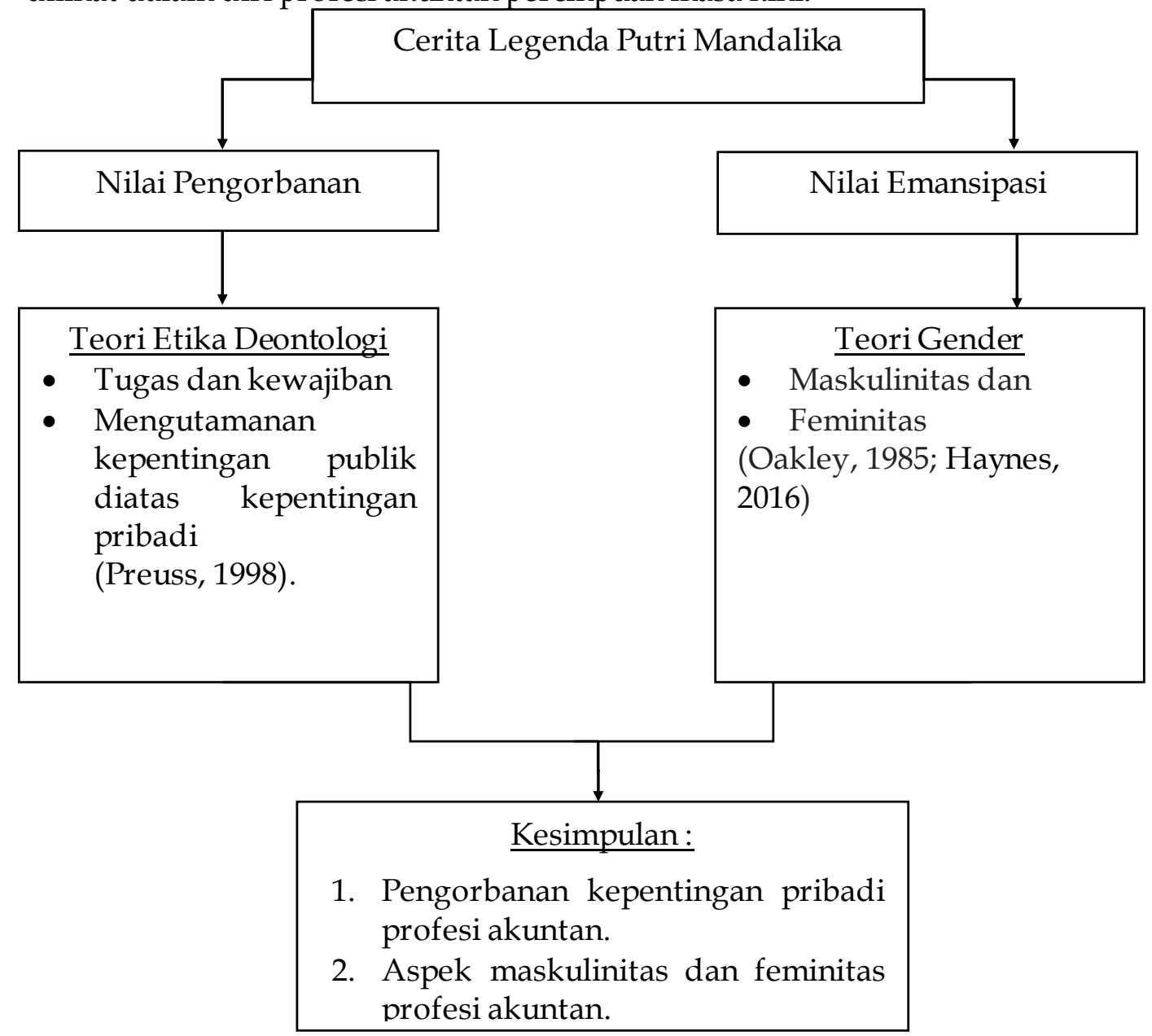

Sumber: Data Penelitian, 2020

Gambar 1. Model Penelitian 


\section{METODE PENELITIAN}

Penelitian ini menggunakan metode penelitian kualitatif dengan paradigma interpretif dan pendekatan fenomenologi. Paradigma interpretif lebih menekankan pada makna atau interpretasi seseorang terhadap sebuah simbol. Burrell \& Morgan (1979:20) menggambarkan sifat interpretif sebagai paradigma yang memiliki karakteristik untuk memahami dan menjelaskan dunia sosial yang tidak terlepas dari kacamata personal yang terlibat langsung dalam sebuah proses sosial. Untuk memahami lebih dalam tentang fenomena pengorbanan akuntan perempuan dan nilai emansipasi yang ditimbulkan dari profesi akuntan perempuan, maka peneliti menggunakan pendekatan fenomenologi. Fenomenologi menurut Husserl adalah pengalaman subjektif atau pengalaman fenomenologikal atau suatu studi tentang kesadaran dari perspektif pokok dari seseorang (Burrell \& Morgan, 1979). Pedoman wawancara yang digunakan adalah sebagai berikut:

Tabel 1. Pedoman Wawancara

\begin{tabular}{|c|c|c|c|}
\hline No. & Pertanyaan & Topik & Informan \\
\hline 1. & $\begin{array}{l}\text { 1. Apa sumber inspirasi } \\
\text { bapak untuk menulis cerita Putri } \\
\text { Denda Mandalika? } \\
\text { 2. Apakah cerita Putri Denda } \\
\text { Mandalika hanya cerita fiktif belaka } \\
\text { atau ada unsur sejarah dibalik cerita } \\
\text { tersebut? } \\
\text { 3. Apa karakter sebenarnya } \\
\text { yang ingin ditonjolkan dalam diri } \\
\text { putri denda mandalika? } \\
\text { 4. Apa harapan yang bapak } \\
\text { inginkan dari menulis cerita Putri } \\
\text { Denda Mandalika bagi para } \\
\text { pembacanya? }\end{array}$ & $\begin{array}{l}\text { Makna } \\
\text { Legenda } \\
\text { Mandalika }\end{array}$ & $\begin{array}{l}\text { Informan 1: } \\
\text { BapakSry Satriya } \\
\text { Tjatur Wisnu } \\
\text { Sasangka }\end{array}$ \\
\hline 2. & $\begin{array}{l}\text { 1. Bagaimana keseharian } \\
\text { Anda dalammembagi waktuantara } \\
\text { karir dan kehidupan pribadi? } \\
\text { 2. Bagaimanakah keyakinan } \\
\text { Anda mengenai kode etik akuntan } \\
\text { publik? } \\
\text { 3. Apakah sulit menerapkan } \\
\text { kode etik akuntan publik pada } \\
\text { praktek kerja? } \\
4 \text { Apakah kendala yang } \\
\text { paling utama dalam mengikuti } \\
\text { kode etikakuntan publik? }\end{array}$ & $\begin{array}{l}\text { Kehidupan Akuntan } \\
\text { Perempuan }\end{array}$ & $\begin{array}{ll}\text { Informan 2: } & \\
\text { Prof. Dr. Ilya } \\
\text { Avianti, } & \text { SE., } \\
\text { M.Si., Ak. } & \end{array}$ \\
\hline
\end{tabular}

Bersambung... 
Lanjutan Tabel 1.

\begin{tabular}{lllll}
\hline 3. & Apa salah satu sifat sebagai & Nilai Moral Putri & Informan 2: \\
perempuan dalam mencerimkan & Mandalika Dalam Prof. Dr. Ilya \\
nilai pengorbananyangadadalam & Diri Akuntan Avianti, & SE., \\
diri Anda? Mengapa? & Perempuan & M.Si., Ak. & \\
2. Apa salah satu sifat sebagai & (Behavioral & \\
perempuan dalam mencerimkan & Accounting) &
\end{tabular}
nilai emansipasi yang ada dalam diri Anda? Mengapa?

Sumber: Data Penelitian, 2020

Teknik pengumpulan data menggunakan metode wawancara terstruktur. Wawancara ini akan dilakukan terhadap 2 informan yaitu Budayawan dan Akuntan Perempuan. Metode wawancara dipilih agar peneliti dapat mengembangkan pertanyaan berdasarkan jawaban informan pada saat dilakukan wawancara. Wawancara dilakukan dengan bertanya langsung kepada informan untuk menggali dan mendapatkan informasi yang berkaitan dengan data yang dibutuhkan. Adapun wawancara dengan menggunakan pedoman wawancara, sehingga peneliti dapat mengembangkan pertanyaan-pertanyaan penelitian sesuai dengan kebutuhan informasi yang diinginkan.

\section{HASIL DAN PEMBAHASAN}

Penelitian ini berangkat dari cerita legenda Putri Mandalika yang menjadi dasar untuk nilai moral figur Putri Mandalika dilihat dalam profesi akuntan, khususnya perempuan. Nilai moral tersebut terdiri dari nilai pengorbanan yang dijelaskan menggunakan teori deontologi (Preuss, 1998) dan nilai emansipasi yang dijelaskan menggunakan teori gender (Haynes, 2016) dan (Oakley, 1985).

Menurut Purna (2018) Putri Mandalika ternyata mampu berbuat sebagaimana sifat kaum lelaki, misalnya keberanian, ketabahan, kepemimpinan dan jiwa patriotisme, dan di samping itu ia juga mendapatkan perlakuan sebagaimana kaum lelaki, yakni dihargai, dihormati, disegani, diberikan kebebasan dan kemerdekaan berpendapat bahkan diharapkan untuk menjadi pemimpin. Hal ini menggambarkan aspek maskulinitas secara jelas dan nyata. Adanya kesadaran akan peran dan andil perempuan dalam pembangunan budaya dan tradisi Putri Mandalika bisa membawa semangat baru kepada Profesi Akuntan khususnya Akuntan Perempuan dalam menetralisir emansipasi tersebut. Pada masa kini, akuntan perempuan tidak hadir sebagai backup system, namun juga memiliki peran dalam pengambilan keputusan. Terbukti dari beberapa penelitian terdahulu yang melihat bagaimana peran akuntan perempuan dalam menjalankan kewajibannya sebagai akuntan.

Puspitaningtyas (2013) menunjukkan peran dan posisi perempuan dalam pekerjaan profesional organisasi baik di bidang akuntansi dan profesi lainnya. Perempuan masih memiliki hak dan kewajiban dan tanggung jawabyang sama dengan pria dalam profesi. Flynn, Earlie, \& Cross (2015) yang menguji persepsi akuntan pria dan wanita tentang perkembangan karir wanita di Profesi Akuntansi di Irlandia menemukan bukti perbedaan antara persepsi dan realitas pengalaman hidup akuntan perempuan, di seluruh kesenjangan gender. 
Responden percaya bahwa mereka belum mengalami hambatan ter kait gend er dalam perkembangan karir mereka, jelas bahwa kedua gender percaya bahwa perempuan berhasil dalam profesi ini dengan beradaptasi dengan nilai-nilai $\mathrm{d}$ an norma-norma kerja maskulin.

Bagaimana akuntan perempuan bertanggungjawab atas pekerjaannya juga dibuktikan oleh penelitian Komalasari yang melihat perempuan pada fase pragmatic endurance model atau perempuan yang berada pada pertengahan karier, yang mulai menghadapi komitmen untuk menjaga keseimbangan professional pekerjaan, kehidupan masyarakat dan kehidupan pribadi/rumah tangga. Hasil penelitian menunjukkan bahwa, multi peran perempuan - karier Bali bersumber pada akuntabilitas diri (self accountability) yang dimilikinya (Komalasari, Wirajaya, \& Sari, 2019).

Untuk memahami lebih dalam nilai moral dari figur Putri Mandalika, peneliti memerlukan Budayawan untuk tujuan menggali dan mengetahui nilai moral Figur Putri Mandalika. Adapun informan yang dipilih sebagai budayawan dalam penelitian ini yaitu Bapak Sry Satriya Tjatur Wisnu Sasangka dipilih sebagai informan karena beliau merupakan penulis cerita legenda Putri Mandalika yang berjudul "Putri Denda Mandalika" diterbitkan oleh Pusat Bahasa Nasional. Beliau adalah lulusan dari S-1 Jurusan bahasa dan sastra Jawa, Universitas Sebelas Maret (UNS), Surakarta (1986) dan S-2 Magister pendidikan, Universitas Negeri Jakarta (2006).

Berdasarkan hasil wawancara dengan Bapak Sry Satriya Tjatur Wisnu Sasangka, alasan Bapak Sry Satriya Tjatur Wisnu Sasangka menulis cerita legenda Putri Mandalika itu sendiri untuk menggambarkan sosok perempuan sasak yang berani berpendapat, tidak egois, dan menunjukkan bahwa perempuan pada masa itu diberikan kekuasaan untuk menentukan sikap. Sebagai putri kerajaan tentu harus memiliki sifat rela berkorban. Begitu juga dengan Putri Mandalika yang dikenal sebagai putri kerjaan yang rela berkor ban seperti yang sudah dikonfirmasi oleh Bapak Sry Satriya Tjatur Wisnu Sasangka.

Sifat rela berkorban dari figur Putri Mandalika dapat dilihat dalam profesi akuntan perempuan dimana praktisi akuntan yang dipilih dalam penelitian ini adalah akuntan perempuan yang sudah menduduki level top management agar dapat melihat bagaimana mereka menyeimbangkan kehidupan sosial seperti privasi, kehidupan rumah tangga dan pengalaman hidupnya dengan profesionalismenya di dalam lingkungan kerja yang berhadapan dengan publik. Adapun informan yang dipilih yaitu Prof. Dr. Ilya Avianti, SE., M.Si., Ak. sebagai auditor BPK-RI, Dewan Komisaris PLN, serta tercatat sebagai Dosen Fakultas Ekonomi Universitas Padjadjaran.

Ibu Ilya Avianti menceritakan bagaimana kehidupannya sebagai istri, ibu, dan berprofesi akuntan. Dengan beberapa jabatan yang diemban, tentu tidak melepaskan tanggungjawabnya sebagai istri dan ibu. Seperti yang dikatakan Ibu Ilya Avianti "untuk segala kebutuhan rumah tangga baik untuk suami atau anak-anak tetap saya kontrol dari jauh karena pekerjaan yang terkadang bisa dinas luar kota, walaupun yang menyiapkan adalah asisten rumah tangga, teteapi saya tetap kontrol lewat handphone". Dari sini dapat ditangkap bahwa ada pengorbanan waktu bersama keluarga yang dihabiskan untuk bekerja. Meskipun demikian, Ibu Ilya 
Avianti sendiri sudah berkomitmen dari awal pernikahan dengan suaminya bahwa tetap akan bertanggungjawab untuk keluarga meskipun harus berkarir sebagai akuntan. Anak-anak dari ibu Ilya Avianti pun mendukung keputusannya dalam berkarir sebagai akuntan. Sehingga, pengorbanan waktu yang telah lebih banyak dihabiskan pada lingkungan kerja terbukti tidak berpengaruh terhadap perkembangan anak. Ibu Ilya Avianti mengkonfirmasikan bahwa "anak-anak saya sudah bisa mandiri dalam mengurus pendidikan dan juga sudah berkeluarga. Mereka juga memiliki kesibukannya masing-masing dengan pekerjaannya. Hanya sekali waktu menyempatkan untuk kumpul bersama, makan bersama pada akhir minggu". Dengan demikian dapat disimpulkan bahwa pengorbanan yang dilakukan oleh akuntan perempuan masa kini adalah dalam bentuk waktu.

Peran perempuan dan keterkaitannya dengan profesi akuntan di kehidupan sosial seperti privasi, kehidupan rumah tangga dan pengalaman hidup seseorang bersinggungan dengan profesionalismenya di dalam lingkungan kerja yang berhadapan dengan publik (Haynes, 2008, 2016). Whiting \& Wright (2001) menyarankan bagi akuntan perempuan untuk bekerja pada tingkatan yang lebih besar, tetapi tetap harus menyeimbangkan antara karir dan tanggung jawab keluarganya. Tentu tidak mudah dalam menyeimbangkan kedua hal tersebut. Asumsikan bahwa dengan menjadi akuntan perempuan, mereka tidak dapat menepati janji kepada anak-anak mereka untuk pergi liburan musim semi ini. Jika demikian, menjadi akuntan mungkin bermanfaat bagi klien, karir akuntan itu sendiri, dan pihak lain yang terlibat dalam pekerjaan tersebut, tetapi tidak adil bagi anak-anak mereka. Dalam situasi seperti ini, ketika ada alasan untuk melakukan sesuatu dan alasan untuk tidak melakukannya, kita dihadapkan dengan dilema etika (Duska, 2011:48). Kemudian, teori etika muncul untuk menyelesaikan dilema.

Ada beberapa teori utama terkait Etika dan salah satunya ada teori etika deontologi. Teori Deontologis dikemukakan pertama kali oleh filsuf Jerman abad ke-18 yaitu Immanuel Kant. Deontologis berasal dari bahasa Yunani "d eontos" yang berarti apa yang harus dilakukan atau juga dapat diartikan sebagai "kewajiban" atau "tugas" (Duska, 2011). Kant \& Schneewind (2002) menjelaskan bahwa tindakan moral sebagai kewajiban moral berbeda dengan tindakan kecenderungan dan keinginan dimana jika seseorang bertindak hanya berdasarkan kecenderungan dan keinginan maka dapat dikatakan bahwa orang tersebut tidak bertindak sesuai dengan moral yang berlaku. Oleh karena itu, kewajiban dapat dikatakan sebagai tindakan baik untuk dilakukan tanpa melihat konsekuensi yang akan diterima (Kant \& Schneewind, 2002). Ketika se seor ang bertindak atas dasar kepentingan tugas dan kepentingan umum dimana tugas menyiratkan pengakuan dan ketaatan terhadap hukun dan ajaran maka kebaikan akan termanifestasikan dengan sendirinya.

Perspektif Deontologis banyak digunakan dalam regulasi di bidang akuntansi, misalnya kebutuhan eksplisit oleh Auditing Practices Committee di AS pada kualifikasi company's accounts padabasis usaha yang berkelanjutan yang menyatakan bahwa auditor tidak boleh menahan diri untuk mempertahankan laporan dari hasil auditnya jika memang tepat hanya karena alasan bahwa hal ini dapat mempengaruhi penunjukkan penerimaan atau likuidator (Moizer, 1995). Oleh karena itu, peneliti memilih teori ini dikarenakan dalam pandangan teori 
etika Deontologis memberikan penjelasan bahwa profesi akuntan harus melaksanakan tugas dan kewajibannya serta mengutamanan kepentingan publik diatas kepentingan pribadi untuk mendapatkan informasi yang akurat tentang kemampuan perusahaan untuk melanjutkan usahanya (Preuss, 1998).

Teori etika deontologi tidak membahas apa akibat atau konsekuensi dari suatu tindakan yang dilakukan. Suatu sikap dapat dibenarkan bukan karena memberikan dampak yang baik, tetapi karena sikap tersebut memang baik dan sikap tersebut merupakan kewajiban yang memang harus dilaksanakan. Dalam kaitannya dengan cerita legenda Putri Mandalika memaknai cerita tersebut sebagai bentuk pengorbanan untuk kebaikan semua orang, Putri Mandalika dapat dikatakan memiliki sifat deontologists. Dalam arti lain, Putri mandalika mengorbankan nyawanya demi menjalankan kewajibannya sebagai putri kerajaan yang harus melind ungi rakyatnya dari berbagai ancaman, terlepas dari dampak dari tindakannya itu baik atau tidak bagi dirinya sendiri.

Profesi akuntan dituntut berdasar kepada kepentingan umum. Hal ini dicantumkan pada Institute of Chartered Accountants of England, Institute of Chartered Accountants of Scotland, dan American Institute of CPA's (Preuss, 1998). Memenuhi kepentingan publik adalah sikap untuk menjaga kepercayaan publik dan profesionalisme dalam menjalankan tugas. Di sisi lain, bagi para akuntan perempuan juga penting untuk menjalankan kehidupan rumah tangganya agar dapat sejalan dengan karir yang sedang dilakoni (Montenegro \& Bras, 2015). Bentuk pengorbanan waktu dari profesi akuntan perempuan mencerminkan sikap etika deontologists.

Nilai lain yang menjadi pembahasan dalam penelitian ini adalah nilai emansipasi. Nilai emansipasi yang tercermin dari diri Putri Mandalika yang memiliki aspek feminisme dan maskulinitas. Aspek feminisme dari Putri Mandalika yaitu memiliki budi pekerti yang mulia, selalu menghormati dan menghargai orang lain, cerdas, arif dan bijaksana, sabar dan lemah lembut. Jiwa seperti ini merupakan jiwa kewanitaan, yang secara psikologis, wanita memiliki perasaan dan nurani halus serta keibuan, yang selalu mudah mengalah, berpikir panjang, mampu mengontrol dan mengendalikan emosinya, nalurinya mampu memahami dan mengerti perasaan orang lain, ramah, pemurah dan perhatian terhadap sesama (Purna, 2018). Menurut Purna (2018), Putri Mandalika terny ata mampu berbuat sebagaimana sifat kaum lelaki, misalnya keberanian, ketabahan, kepemimpinan dan jiwa patriotisme, dan di samping itu ia juga mendapatkan perlakuan sebagaimana kaum lelaki, yakni dihargai, dihormati, disegani, diberikan kebebasan dan kemerdekaan berpendapat bahkan diharapkan untuk menjadi pemimpin. Hal ini menggambarkan aspek maskulinitas secara jelas d an nyata.

Aspek feminitas dan maskulinitas dijelaskan dalam teori gender sebagai konsep yang diterima secara luas untuk dibangun secara sosial (Haynes, 2016) dan (Oakley, 1985). Hubungan gender adalah hasil dari kondisi dan proses sosial-budaya dan historis di mana orang menafsirkan dan menciptakan kembali dunia sosial (Alvesson \& Billing, 1997) dan (Haynes, 2016). Dapat disimpulkan bahwa pengertian gender adalah perbedaan perlakuan terhadap laki-laki dan wanita berdasar konstruksi sosial, yaitu perbedaan yang bukan karena kodrat 
atau bukan ciptaan Tuhan, melainkan diciptakan baik oleh laki-laki maupun oleh perempuan itu sendiri melalui proses sosial-budaya yang panjang.

Kesetaraan gender merupakan kondisi perempuan dan laki-laki menikmati status yang setara dan memiliki kondisi yang sama untuk mewujudkan secara penuh hak-hak asasi dan potensinya bagi pembangunan di segala bidang kehidupan. Kesetaraan gender memberi kesempatan baika pada perempuan maupun laki-laki untuk secara setara/sama/sebanding menikmati hak-haknya sebagai manusia, secara sosial mempunyai benda-benda, kesempatan, sumberdaya dan menikmati manfaat dari hasil pembangunan. Karena itu gender adalah efek sosial definisi dan internalisasi makna menjadi pria atau wanita (Haynes, 2016). Dalam keseteraan gender terdapat aspek feminism dan maskulin sering diperhatikan. Dimana feminism bertujuan untuk menghilangkan kelas sosial yang ada dimasyarakat (Megawangi, 1999) sedangkan maskulin merupakan perilaku sempurna artinya memiliki standar capaian yang tinggi.

Seperti yang telah ditegaskan oleh Bapak Sry Satriya Tjatur Wisnu Sasangka bahwa "perempuan itu harus berani mengambil sikap dan berpikir realistis". Maksudnya adalah bagaimana figur Putri Mandalika ini mengambil sikap sudah menunjukkan bahwa perempuan juga bisa setara dengan laki-laki, yaitu diberikan kebebasan untuk mengambil keputusan. Pada masa kini, nilai emansipasi terus menerus disosialisasikan agar para perempuan berani untuk mengambil sikap dan tidak ditindas oleh kaum lelaki. Hal ini pun dibuktikan oleh Ibu Ilya Avianti yang mampu menjabat pada posisi tinggi sebagai dewan komisaris PLN dimana dalam pekerjaan tersebut banyak mengambil keputusankeputusan penting bagi perusahaan dan semua itu dilakukan oleh seorang perempuan. Ibu Ilya Avianti juga mengkonfirmasi bahwa "dalam pekerjaan saya tidak memiliki hambatan untuk berhubungan kerja dengan rekan laki-laki, semua diperlakukan sama sesuai tanggungjawabnya, tidak memandang itu laki-laki atau perempuan".

Sisi feminitas dan maskulinitas juga digali pada profesi akuntan perempuan masa kini. Seperti ibu Ilya Avianti mengungkapkan bahwa "yang terpenting dalam setiap pekerjaan itu adalah kita harus memiliki integritas. Apapun kondisinya jika tindakan kita benar dan sudah mengikuti kode etik yang berlaku, maka tidak ada yang perlu dikhawatirkan". Sikap integritas juga bisa termasuk ke dalam sisi maskulinitas, begitu juga dengan sikap berani mengambil keputusan, sikap kepemimpinan adalah sikap-sikap sisi maskulinitas dari profesi akuntan. Di sisi lain adalah feminitas yang timbul dari profesi akuntan perempuan dimana tut ur kata yang lembut, bagaimana cara berpenampilan yang rapi dan anggun, serta memperhatikan rekan kerja. Semua ini dapat dilihat dari hasil observasi pada lingkungan kerja ibu Ilya Avianti. Dengan demikian, dapat disimpulkan bahwa nilai emansipasi yang dibawa oleh figur Putri Mandalika juga masih ad a dalam profesi akuntan masa kini.

\section{SIMPULAN}

Kesimpulan dari penelitian ini adalah nilai pengorbanan yang dicerminkan pada figur Putri Mandalika yaitu rela mengorbankan apapun demi kepentingan rakyatnya masih hidup dalam profesi akuntan masa kini dalam bentuk 
pengorbanan waktu bersama keluarga yang dihabiskan untuk berkarir sebagai akuntan publik yang memiliki tanggungjawab untuk kepentingan publik.

Nilai emansipasi yang dibawa oleh Putri Mandalika yang didukung dari sisi feminitas dan maskulinitas masih ditunjukkan oleh profesi akuntan perempuan berupa sikap integritas yang tinggi, sikap berani mengambil keputusan, sikap kepemimpinan yang menunjukkan sisi maskulinitas dari profesi akuntan. Tutur kata yang lembut, bagaimana cara berpenampilan yang rapi dan anggun, serta memperhatikan rekan kerja menunjukkan sisi feminitas dari profesi akuntan perempuan.

Kelemahan dari penelitian ini adalah kurangnya informan praktisi akuntan perempuan. Penelitian selanjutnya dapat menambah informan lebih banyak lagi sehingga dapat memperluas gambaran nilai moral figur Putri Mandalika.

\section{REFERENSI}

Akenbor, C. O., \& Tennyson, O. (2014). Ethics of Accounting Profession in Nigeria. Joumal of Business and Economics, 5(8), 1374-1382.

Alvesson, M., \& Billing, Y. D. (1997). Understanding Gender and Organization (1st ed.). SAGE.

Ariefa, N. A., \& Mutiawanthi. (2018). Perempuan Pada Cerita Rakyat Jepang dan Indonesia: Analisis Komparatif dengan Pendekatan Feminisme. Jurnal Al-Azhar Indonesia Seri Humaniora, 4(3), 150-160.

Burrell, G., \& Morgan, G. (1979). Sociological paradigms and organizational analysis. London: Heineman.

Collins, A., \& Schultz, N. (1995). A Critical Examination of the AICPA Code of Professional Conduct. Journal of Business Ethics, 14(1), 31-41.

Duska, R. F. (2011). Accounting Ethics. Wiley Blackwell.

Flynn, A., Earlie, E. K., \& Cross, C. (2015). Gender equality in the accounting profession: one size fits all. Gender in Management: An International Journal, 30(6), 479-499.

Hartono, S., \& Faozaeni, E. (2018). Mandalika Punya Kita. Exotica Senggigi.

Haynes, K. (2008). Transforming identities: Accounting professionals and the transition to motherhood. Critical Perspectives on Accounting , 19(5), 620642.

Haynes, K. (2016). Accounting as gendering and gendered : A review of 25 years of critical accounting research on gender. Critical Perspectives on Accounting. $\quad$ Retrieved from http://dx.doi.org/10.1016/j.cpa.2016.06.004

Kant, I., \& Schneewind, J. B. (2002). Groundwork for the Metaphysics of Morals. Yale University Press.

Komalasari, Y., Wirajaya, I. G. A., \& Sari, M. M. R. (2019). Akuntabilitas Akuntan Perempuan-Karir Bali: Sebuah Studi Fenomenologi. Jurnal Ilmiah Akuntansi Dan Bisnis, 14(1), 70-85.

Megawangi, R. (1999). Membiarkan berbeda?: Sudut pandang baru tentang relasi gender. Mizan. 
Moizer, P. (1995). An ethical approach to the choices faced by auditors. Critical Perspectives on Accounting, 6, 415-431.

Montenegro, T. M., \& Bras, F. A. (2015). Audit quality: does gender composition of audit firms matter? Spanish Journal of Finance and Accounting, 44(July), 264-297.

Oakley, A. (1985). Sex, Gender and Society. Ashgate Publishing Limited.

Preuss, L. (1998). On ethical theory in auditing. Managerial Auditing Journal, 13(9), 500-508.

Purna, I. M. (2018). Bau Nyale: Tradisi Bernilai Multikulturalisme dan Pluralisme. Patanjala, 10, 99-114.

Puspitaningtyas, Z. (2013). Perempuan dalam perspektif akuntansi syariah. Jumal Ilmu Ekonomi Dan Sosial, 2, 206-214.

Rosnilawati. (2016). Studi Komparatif Struktur Cerita Legenda La Hila (Bima) dan Legenda Putri Mandalika (Lombok). Universitas Mataram.

Sasangka, S. S. T. W. (2002). Putri Denda Mandalika. Jakarta: Pusat Bahasa.

Whiting, R. H., \& Wright, C. (2001). Explaining gender inequity in the New Zealand accounting profession. British Accounting Review, 33(March 2000), 191-222. 